\title{
Dynamic Analysis of Pipes Conveying Fluid Using Analytical, Numerical and Experimental Verification with the Aid of Smart Materials
}

\author{
Dr. Muhsin J. Jweeg ${ }^{1}$, Thaier J. Ntayeesh ${ }^{2}$ \\ ${ }^{1}$ Professor, Mechanical Engineering Department, AL_Nahrain University, Baghdad, Iraq, \\ ${ }^{2}$ Mechanical Engineering Department, University of Baghdad, Baghdad, Iraq
}

\begin{abstract}
Pipes conveying fluid have significant applications in a wide range of industrial and engineering applications. Recently, this topic has been crystallized into a dynamical model for analyzing the fluid-structure-interaction (FSI) which has vast applications in aerospace, aerodynamics, ship motion, medical engineering..etc. In order to provide an alternative analysis of the dynamical behavior and stability of pipes conveying fluid, analytical solution was attempted .The attempted solutions are based on Galerkin's methods to finding the natural frequency at different boundary conditions and velocities. Experimental work was carried out by built a rig which was mainly composed of a different boundary conditions of pipes conveying fluid and provided with the necessary measurement equipments to fulfill the required investigations. Results presented in this study compared with the results performed by using analytical solution for equation of motion. Also, compared with the results performed by using ANSYS CFX program, this analysis based on the numerical solution; using Finite element method to formulate both the structure and fluid flow equations. The experimental results show satisfactory agreement with the theory many aspects of the dynamical behaviour of pipe conveying fluid were observed experimentally such as: the decrease in natural frequencies with increasing of the fluid velocity. Very little effect was observed for the velocity ranges used.
\end{abstract}

Keywords: Pipe conveying fluid, Natural frequency, Smart materials.

\section{Introduction}

Pipes conveying fluid are of considerable interest in many engineering fields. They are widely used in various industrial branches. Sometimes, their role is simply to transport fluids, as in oil pipelines, pump discharge lines, propellant lines and municipal water supply. In other cases, they provide basic structural components as in power plants, chemical plants, hydraulic systems, chemical plants, liquid-fuel rocket piping components, refrigerators, air-conditioners, heat exchangers, and so on.

The problem of pipes conveying fluid belongs to the broader class of dynamical problems involving axially moving continua such as traveling strings bands, belts, magnetic tapes and chain saws.

Due to its significance in science this topic may be taken as a new paradigm of interesting dynamical behavior to develop nonlinear dynamics, projecting them as a model dynamical problem[1,2].

In general ,the dynamical behavior of pipes conveying fluid are more complicated than the corresponding structure without fluid .In the latter case, free vibrations for a specified structure (degree of freedom and boundary conditions) depend only on its mass and stiffness. In such structures the Eigen values are related to structure parameters, hence the natural frequency is unique .In this case the vibrations are of uncontrolled type .If however, such structures are subjected to an axial force ,it is seen that the Eigen values are affected by the amount and direction of this force .In other words if this force is compressive the natural frequencies decrease with the increasing of this force .In this case vibration is controlled by this force and there is a critical value of this force at which the fundamental frequency drops to zero leading to buckling state.

When the structure interacts with a fluid media such as pipe conveying fluid different phenomena might occur according to the effects of the internal forces between the elastic structure and the fluid .Thus, the vibrations are of controlled type.

As compared with the ordinary elastic structures (without fluid), the linear dynamical behavior of pipe conveying fluid has the following significant differences[3];

1) It is complex boundary-value problems.

2) Classical normal (orthogonal) modes never exist) .

3) The natural frequencies may become complex.

4) The natural frequencies are controlled by the fluid-pipe parameters.

The fluid conveyed pipes exhibit wide array of dynamical behaviors due to the effect of the large number of parameters associated with the pipe structure and the conveyed fluid such as;

1. Various pipe support conditions,

2. Articulated or continuous configuration,

3. Straight or curved shape,

4. Single or multi- span,

5. Additional system attachments like lumped mass, nozzles, elastic foundations, elastic constraints,

6. Different forms of nonlinearities in the system arising from various sources; such as fluid flow fluctuation ,axial extension ,thermal stresses ,nonlinear damping and

\section{Volume 4 Issue 12, December 2015}




\section{International Journal of Science and Research (IJSR) \\ ISSN (Online): 2319-7064}

Index Copernicus Value (2013): 6.14 | Impact Factor (2014): 5.611

nonlinear material behavior,

7. Fluid parameters and properties such as velocity, pressure, viscosity, density, temperature, additives, vortices .etc.

In the present work, the linear analysis of vibrations and stability of initially straight pipes conveying fluid will be considered.The analysis will include all the classical boundary conditions.

\section{Dynamic Analysis of Pipes Conveying Fluid}

Consider a straight uniform pipe conveying fluid of length $\mathrm{L}$. The following assumptions are considered in the analysis of the system under consideration [4]:

1)Neglecting the effect of gravity.

2)The pipe considered to be horizontal.

3) Neglecting the material damping.

4) The pipe is inextensible.

5)Neglecting the shear deformation and rotary inertia.

6)All motion considered small.

7) Neglecting the velocity distribution through the crosssection of the pipe.

Derivation of the equation of motion for straight pipe with steady flow are available in the literature Ref.[5].For a single-span pipe conveying fluid, the equation based on beam theory is given by,

$$
E I \frac{\partial^{4} y}{\partial x^{4}}+\left(M U^{2}+P A\right) \frac{\partial^{2} y}{\partial x^{2}}+2 M U \frac{\partial^{2} y}{\partial x \partial t}+(M+m) \frac{\partial^{2} y}{\partial t^{2}}=0
$$

where $F(x, t)$ : is the external harmonic force being applied normally to the pipe axis in the $y$-direction.

$E I \frac{\partial^{4} y}{\partial x^{4}}$ : Stiffness term

$\left(M U^{2}+P A\right) \frac{\partial^{2} y}{\partial x^{2}}:$ Curvature term

$2 M U \frac{\partial^{2} y}{\partial x \partial t}:$ Coriolis force term

$(M+m) \frac{\partial^{2} y}{\partial t^{2}}:$ Inertia force term

The Coriolis force is a result of the rotation of the system element due to the system lateral motion, since each point in the span rotates with angular velocity [6].

The equation of motion Eq.(1) can be written in the following non-dimensional form:

$$
\ddot{\eta}+2 M_{r} u_{0} \dot{\eta}^{\prime}+\left[u_{0}{ }^{2}+\Pi\right] \eta^{\prime \prime}+\eta^{(4)}=0
$$

Where,

$\xi=x / L$

$\eta=y / L$

$\eta^{(4)}=\frac{\partial^{4} y}{\partial x^{4}}, \eta^{(2)}=\frac{\partial^{2} y}{\partial x^{2}}, \dot{\eta}^{r}=\frac{\partial^{2} y}{\partial x \partial t}, \ddot{\eta}=\frac{\partial^{2} y}{\partial t^{2}}$,

$\tau=\sqrt{E I /(M+M)}\left(\frac{t}{L^{2}}\right)$.

$M_{r}=\sqrt{M /(M+m)}, u_{0}=U L \sqrt{(M / E I)}$

$\Pi=\left(\frac{P A}{E I}\right) L^{2}$

$M_{r}$ : Non-dimensional mass ratio.

$\Pi$ : Non-dimensional fluid pressure.
The motion equation above is inhomogeneous, as the derivative coefficients of $\eta$ are explicit functions of $\xi$ and $\tau$. Then we discretize Eq. (2) using the Galerkin's method. Let

$$
\eta(\xi, \tau)=\sum_{i=1}^{\infty} \phi_{i}(\xi) q_{i}(\tau)
$$

$q_{i}(\tau)$ is an generalized coordinate, $\phi_{i}(\xi)$ is an comparison function which satisfies all the boundary conditions. Selecting the first three orders conducts researches, which is: $\eta(\xi, \tau)=\sum_{i=1}^{3} \phi_{i}(\xi) q_{i}(\tau)=\phi_{1}(\xi) q_{1}(\tau)+\phi_{2}(\xi) q_{2}(\tau)+\phi_{3}(\xi) q_{3}(\tau)$

For pinned at both ends of pipes, its vibration model function is:

$$
\phi_{i}=\sqrt{2} \sin \left(\lambda_{i} \xi\right), \quad i=1,2,3
$$

Where $\lambda 1, \lambda 2$ and $\lambda 3$ are beam eigenvalues $\lambda 1=\pi, \lambda 2=2 \pi, \lambda 3=3 \pi$.

For fixed at both ends of pipes, its vibration model function is:

$$
\begin{aligned}
& \Phi_{i}=\cosh \left(\lambda_{i} \xi\right)-\cos \left(\lambda_{i} \xi\right)+ \\
& \frac{\cosh \left(\lambda_{i}\right)-\cos \left(\lambda_{i}\right)}{\sinh \left(\lambda_{i}\right)-\sin \left(\lambda_{i}\right)}\left[\sin \left(\lambda_{i} \xi\right)-\sinh \left(\lambda_{i} \xi\right)\right], i=1,2,3
\end{aligned}
$$

Where $\lambda 1=4.7300, \lambda 2=7.8532, \lambda 3=10.9956$.

For fixed at one end and pinned at other end of pipes, its vibration model function is:

$$
\begin{aligned}
& \Phi_{i}=\cos \left(\lambda_{i} \xi\right)-\cosh \left(\lambda_{i} \xi\right)- \\
& \frac{\cos \left(\lambda_{i}\right)-\cosh \left(\lambda_{i}\right)}{\sin \left(\lambda_{i}\right)-\sinh \left(\lambda_{i}\right)}\left[\sin \left(\lambda_{i} \xi\right)-\sinh \left(\lambda_{i} \xi\right)\right], i=1,2,3
\end{aligned}
$$

Where $\lambda 1=3.9267, \lambda 2=7.0686, \lambda 3=10.2102$

For cantilever pipe, its vibration model function is:

$\Phi_{i}=\cosh \left(\lambda_{i} \xi\right)-\cos \left(\lambda_{i} \xi\right)+$ $\frac{\sinh \left(\lambda_{i}\right)-\sin \left(\lambda_{i}\right)}{\cosh \left(\lambda_{i}\right)+\cos \left(\lambda_{i}\right)}\left[\sin \left(\lambda_{i} \xi\right)-\sinh \left(\lambda_{i} \xi\right)\right], i=1,2,3$

Where $\lambda 1=1.87512, \lambda 2=4.6941, \lambda 3=7.85476$

Eq.(3) is changed into matrix type, supposing $\Phi=\left\{\begin{array}{l}\phi_{1} \\ \phi_{2} \\ \phi_{3}\end{array}\right\}, Q=\left\{\begin{array}{l}q_{1} \\ q_{2} \\ q_{3}\end{array}\right\}$, then

$$
\eta(\xi, \tau)=\Phi^{T} Q=Q^{T} \Phi
$$

Plugging (9) into (2), and supposing $H=u_{0}{ }^{2}+\Pi$, then:

$$
\phi^{T} \ddot{Q}+2 M_{r} u_{0} \phi^{r T} \dot{Q}+H \phi^{n T} Q+\phi^{(4) T} Q=0
$$

By multiplying $\Phi=\left\{\begin{array}{l}\phi_{1} \\ \phi_{2} \\ \phi_{3}\end{array}\right\}$ with two sides of (10) and then

$$
\Phi \Phi^{T} \ddot{Q}+2 M_{r} u_{0} \Phi \Phi^{r T} \dot{Q}+H \Phi \Phi^{n T} Q+\Phi \Phi^{(4) T} Q
$$

Conducting $\xi$ integral to (11) at interval [0, 1], and substitutions based on orthogonality of trigonometric function: 


$$
\begin{aligned}
& \int_{0}^{1} \phi \phi^{T} d \xi=I=\left(\begin{array}{ccc}
\int_{0}^{1} \phi_{1} \phi_{1}{ }^{T} & \int_{0}^{1} \phi_{2} \phi_{1}{ }^{T} & \int_{0}^{1} \phi_{3} \phi_{1}{ }^{T} \\
\int_{0}^{1} \phi_{1} \phi_{2}{ }^{T} & \int_{0}^{1} \phi_{2} \phi_{2}{ }^{T} & \int_{0}^{1} \phi_{3} \phi_{2}{ }^{T} \\
\int_{0}^{1} \phi_{1} \phi_{3}{ }^{T} & \int_{0}^{1} \phi_{2} \phi_{3}{ }^{T} & \int_{0}^{1} \phi_{3} \phi_{3}{ }^{T}
\end{array}\right) d \xi= \\
& \left(\begin{array}{lll}
1 & & \\
& 1 & \\
& & 1
\end{array}\right) \text {. } \\
& \int_{0}^{1} \phi \phi^{\prime \tau} d \xi=B=\left(\begin{array}{lll}
\int_{0}^{1} \phi_{1} \phi_{1}{ }^{\prime \tau} & \int_{0}^{1} \phi_{2} \phi_{1}{ }^{\prime \tau} & \int_{0}^{1} \phi_{3} \phi_{1}{ }^{2} \\
\int_{0}^{1} \phi_{1} \phi_{2}{ }^{\prime \tau} & \int_{0}^{1} \phi_{2} \phi_{2}{ }^{\prime \tau} & \int_{0}^{1} \phi_{3} \phi_{2}{ }^{2} \\
\int_{0}^{1} \phi_{1} \phi_{3}{ }^{\prime \tau} & \int_{0}^{1} \phi_{2} \phi_{3}{ }^{\prime \tau} & \int_{0}^{1} \phi_{3} \phi_{3}{ }^{2}
\end{array}\right) d \xi= \\
& \left(\begin{array}{lll}
b_{11} & b_{12} & b_{13} \\
b_{21} & b_{22} & b_{23} \\
b_{31} & b_{32} & b_{33}
\end{array}\right) \text {, } \\
& \int_{0}^{1} \phi \phi^{\prime \prime} \tau d \xi=C= \\
& \left(\begin{array}{lll}
\int_{0}^{1} \phi_{1} \phi_{1}{ }^{\prime \prime \tau} & \int_{0}^{1} \phi_{2} \phi_{1}{ }^{\prime \prime} \tau & \int_{0}^{1} \phi_{3} \phi_{1}{ }^{\prime \prime} \tau \\
\int_{0}^{1} \phi_{1} \phi_{2}{ }^{\prime \prime \tau} & \int_{0}^{1} \phi_{2} \phi_{2}{ }^{\prime \prime T} & \int_{0}^{1} \phi_{3} \phi_{2}{ }^{\prime \prime} \tau \\
\int_{0}^{1} \phi_{1} \phi_{3}{ }^{\prime \prime \tau} & \int_{0}^{1} \phi_{2} \phi_{3}{ }^{\prime \prime} \tau & \int_{0}^{1} \phi_{3} \phi_{3}{ }^{\prime \prime} \tau
\end{array}\right) d \xi= \\
& \left(\begin{array}{lll}
c_{11} & c_{12} & c_{13} \\
c_{21} & c_{22} & c_{23} \\
c_{31} & c_{32} & c_{33}
\end{array}\right) \\
& \int_{0}^{1} \phi \phi^{(4) \tau} d \xi=\Lambda= \\
& \left(\begin{array}{lll}
\int_{0}^{1} \phi_{1} \phi_{1}{ }^{(4) \tau} & \int_{0}^{1} \phi_{2} \phi_{1}{ }^{(4) T} \tau & \int_{0}^{1} \phi_{3} \phi_{1}{ }^{(4) \tau} \\
\int_{0}^{1} \phi_{1} \phi_{2}{ }^{(4) \tau} \tau & \int_{0}^{1} \phi_{2} \phi_{2}{ }^{(4) \tau} \tau & \int_{0}^{1} \phi_{3} \phi_{2}{ }^{(4) \tau} \tau \\
\int_{0}^{1} \phi_{1} \phi_{3}{ }^{(4) \tau} & \int_{0}^{1} \phi_{2} \phi_{3}{ }^{(4) \tau} & \int_{0}^{1} \phi_{3} \phi_{3}{ }^{(4) \tau}
\end{array}\right) d \xi= \\
& \left(\begin{array}{lll}
\lambda_{1}{ }^{4} & & \\
& \lambda_{2}{ }^{4} & \\
& & \lambda_{3}{ }^{4}
\end{array}\right)
\end{aligned}
$$

$\phi_{1}, \phi_{2}$ and $\phi_{3}$ are the first three mode functions for specific boundary conditions.

For pinned at both ends of pipes, the matrix $\mathrm{B}$ and $\mathrm{C}$ are:

$B=\left(\begin{array}{ccc}0 & -2.6667 & 0 \\ 2.6667 & 0 & -4.8 \\ 0 & 4.8 & 0\end{array}\right), C=\left(\begin{array}{ccc}-\left(\pi^{2}\right) & 0 & 0 \\ 0 & -\left(2 \pi^{2}\right) & 0 \\ 0 & 0 & -\left(3 \pi^{2}\right)\end{array}\right)$

For fixed at both ends of pipes, the matrix $\mathrm{B}$ and $\mathrm{C}$ are:

$B=\left(\begin{array}{ccc}0 & -3.3421 & 0 \\ 3.3421 & 0 & -5.5161 \\ 0 & 5.5161 & 0\end{array}\right), C=\left(\begin{array}{ccc}-12.3028 & 0 & 9.7315 \\ 0 & -46.0501 & 0 \\ 9.7315 & 0 & -98.9047\end{array}\right)$

For fixed at one end and pinned at other end of pipes, the matrix $\mathrm{B}$ and $\mathrm{C}$ are:

$B=\left(\begin{array}{ccc}0 & -2.9965 & 0.3167 \\ 2.9965 & 0 & -5.1468 \\ -0.3167 & 5.1468 & 0\end{array}\right), C=\left(\begin{array}{ccc}-11.5126 & 4.2814 & 3.7993 \\ 4.2814 & -42.8964 & 7.81913 \\ 3.7993 & 7.8191 & -94.0376\end{array}\right)$

For cantilever pipe, the matrix $\mathrm{B}$ and $\mathrm{C}$ are:

$B=\left(\begin{array}{ccc}2 & -4.75948 & 3.78433 \\ 0.75948 & 2 & -6.22218 \\ 0.21566 & 2.22218 & 2\end{array}\right), C=\left(\begin{array}{ccc}0.8581 & -11.7433 & 27.4531 \\ 1.8738 & -13.2942 & -9.04205 \\ 1.56453 & 3.22935 & -45.9043\end{array}\right)$

Using equations of (12), the discretized equation after reduced order through (11) is showed below:

$I \ddot{Q}+2 M_{r} u_{0} B \dot{Q}+(C H+A) Q=0$

Where $\ddot{Q}=\left\{\begin{array}{l}\vec{q}_{1} \\ \bar{q}_{2} \\ \bar{q}_{3}\end{array}\right\}, \dot{Q}=\left\{\begin{array}{l}q_{1} \\ q_{2} \\ q_{3}\end{array}\right\}, Q=\left\{\begin{array}{l}q_{1} \\ q_{2} \\ q_{3}\end{array}\right\}$

When $\dot{Q}=\Omega \dot{i}, \ddot{Q}=-\Omega^{2}$, and Eq. (13) become;

$$
\begin{aligned}
& {\left[-I \Omega^{2}+2 M_{r} u_{0} B \Omega i+(C H+A)\right] Q=0} \\
& {\left[-I \Omega^{2}+2 M_{r} u_{0} B \Omega i+(C H+A)\right]=S=\left(\begin{array}{lll}
\mathrm{s}_{11} & \mathrm{~s}_{12} & (14) \\
\mathrm{s}_{21} & \mathrm{~s}_{22} & \mathrm{~s}_{23} \\
\mathrm{~s}_{31} & \mathrm{~s}_{32} & \mathrm{~s}_{33}
\end{array}\right)}
\end{aligned}
$$

$$
\begin{aligned}
& \text { Where } \\
& \mathrm{s}_{11}=\lambda_{1}{ }^{4}+H c_{11}+2 M_{r} u_{0} \mathrm{~b}_{11} \Omega i-\Omega^{2} \\
& \mathrm{~s}_{12}=H c_{12}+2 M_{r} u_{0} \mathrm{~b}_{12} \Omega i \\
& \mathrm{~s}_{13}=H c_{13}+2 M_{r} u_{0} \mathrm{~b}_{13} \Omega i \\
& \mathrm{~s}_{21}=H c_{21}+2 M_{r} u_{0} \mathrm{~b}_{21} \Omega i \\
& \mathrm{~s}_{22}=\lambda_{2}{ }^{4}+H c_{22}+2 M_{r} u_{0} \mathrm{~b}_{22} \Omega i-\Omega^{2} \\
& \mathrm{~s}_{23}=H c_{23}+2 M_{r} u_{0} \mathrm{~b}_{23} \Omega i \\
& \mathrm{~s}_{31}=H c_{31}+2 M_{r} u_{0} \mathrm{~b}_{31} \Omega i \\
& \mathrm{~s}_{31}=H c_{31}+2 M_{r} u_{0} \mathrm{~b}_{31} \Omega i \\
& \mathrm{~s}_{32}=H c_{32}+2 M_{r} u_{0} \mathrm{~b}_{32} \Omega i \\
& \mathrm{~s}_{33}=\lambda_{3}{ }^{4}+H c_{33}+2 M_{r} u_{0} \mathrm{~b}_{33} \Omega i-\Omega^{2}
\end{aligned}
$$

tural frequency $(\Omega)$ is evaluated by setting $|S|$ equal to characteristic equation;

$\Omega^{6}-k_{5} \Omega^{5} i-k_{4} \Omega^{4}-k_{3} \Omega^{3} i-k_{2} \Omega^{2}-k_{1} \Omega i-k_{0}=0$

Where $k_{5}, k_{4}, k_{3}, k_{2}, k_{1}$ and $k_{0}$ are constants depending on

\section{Finite Element Modeling Procedure}

In this section a numerical analysis was adopted by using finite element approach (FEA) to calculate vibration characteristics of pipe conveying fluid with different boundary conditions using a general purpose package ANSYS V12.0. Workbench comes into its own when it comes to build multi-stage workflows, where separate analysis systems work together as shown in Fig. (1). It can start with a fluid flow simulation to find the pressure whes in iner surface of pipe. These pres can then be automatically applied to a structural analysis simulation to

In simulation terms this type of analysis is extremely complex. Most fluid flow simulation technology uses completely different meshing, loading and solving methods compared to structural simulation. The software has the ability to transform meshes between the two disciplines and to ensure that parameters and variables remain consistent where needed.

Modal analysis also used in workbench to determine the vibration characteristics (natural frequencies and mode shapes) of a structure. The approach is divided into four parts: computational fluid dynamics (CFD), structure analysis, coupled field fluid-structure analysis and modal analysis.

\subsection{ANSYS CFX fluid model}

The ANSYS CFX solver uses finite elements (cell vertex numerics), similar to those used in structural analysis, to discretize the domain. The fluid pressure results from ANSYS CFX v12.0 can be easily transferred into ANSYS Workbench for a Structure analysis.

Large eddy simulation (LES) is used as a turbulence model. The largest eddies, having dynamic and geometric properties related to the mean fluid flow; contain more energy than the smallest eddies. The LES approach makes use of this fact by applying spatial filters to the governing equations to remove the smallest eddies while the large eddies are numerically 


\section{International Journal of Science and Research (IJSR) \\ ISSN (Online): 2319-7064}

Index Copernicus Value (2013): 6.14 | Impact Factor (2014): 5.611

simulated. LES does take more computation than the commonly used Reynolds averaged Navier-Stokes (RANS) turbulence models, but RANS models do not resolve the turbulent pressure fluctuations responsible for the pipe vibration of interest. Shurtz [7].

The mesh created for finite element model by dividing the geometry into nodes and elements. The ANSYS program can automatically generate the nodes and elements after specifying the element attributes and sizes.

The next step of the analysis involves applying the appropriate boundary and Initial conditions. The cylindrical surface of the domain is defined as a solid wall with the noslip, smooth wall pipes condition being enforced. The periodic boundary will let the flow develop as it effectively re-enters the inlet each time it has passed through the entire domain

\subsection{Structural model and transient response}

The structural model of the pipe was created using ANSYS Multiphysics. This model experiences transient deformation in response to pressure fluctuations calculated by the fluid model. It uses the finite element method (FEM). Similar to the fluid model, the structural model is solved in a defined region or domain, which is discretized into elements. Portions of the domain are defined as boundaries where the solution I restricted, or forced to match prescribed conditions. The physical properties of the material represented in the domain are specified and the fluid pressure results obtained from the ANSYS CFX v12.0 can be mapped into ANSYS Workbench v12.0 as imported pressure loading for the static stress analysis [8]. Finally, the solver approach is chosen and the solution I obtained. The flow chart for the FSI analysis is shown in appendix[ Fig. (2)].

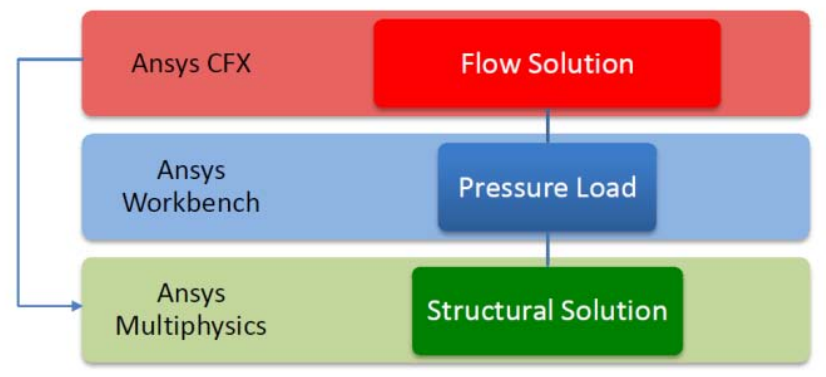

Figure 2: FSI Flow Chart.

\section{Experimental Work}

The aim of this work is to measure the natural frequencies of two samples of pipes conveying water at different boundary conditions, study the effect of fluid velocity on the natural frequencies.

\subsection{Test Models.}

For measuring the natural frequencies and investigating the effect of the fluid velocity on the natural frequencies, and calculating the dynamic behavior of the pipe for the uncontrolled and controlled responses, two pipe models were prepared. Table (1) shows the main specifications of these models.

Table 1: Specifications of the test models

\begin{tabular}{|c|c|c|c|}
\hline Model No. & Material & $\mathbf{D}_{\mathbf{0}}(\mathbf{m})$ & Thickness $(\mathbf{m})$ \\
\hline 1 & PVC & 0.011 & 0.0011 \\
\hline
\end{tabular}

\subsection{Experimental Rig}

The rig consists of two main parts; the foundation and the two Substrates. It was constructed from $(120 \mathrm{cmx} 40 \mathrm{cmx} 1 \mathrm{~cm})$ rectangular section iron plate foundation and two $(22 \mathrm{~cm} \times 20 \mathrm{~cm} x 1 \mathrm{~cm})$ Substrates of pipe support as shown in appendix [Fig.(3)].

The two Substrates were designed to fulfill the various requirements for pinned and clamped conditions. They consisted of two main parts; the iron base and the ball bearing case. The ball bearing has free vertical movement, which leads to zero moment in pin support.

For pin support, a one ball-bearing was used to insure zero moment and displacement see appendix [ Fig.(4a)].

For clamped support, two ball-bearing (Separated by a distance of $3 \mathrm{~cm}$ ) were used to insure zero slope and displacement necessary for clamped end condition, see appendix [Fig.(4b)].

\subsection{Water Circuit}

In all tests, water was used as a flowing fluid .To measure the water flow rate a flowmeter was fitted at the inlet of the test model. The water circuit is shown in Fig.(5). The main components of this circuit are the collecting tank (150 Lit.), centrifugal pump (100 Lit/min., $25 \mathrm{~m})$, control valve (gate type) and the test pipe model.

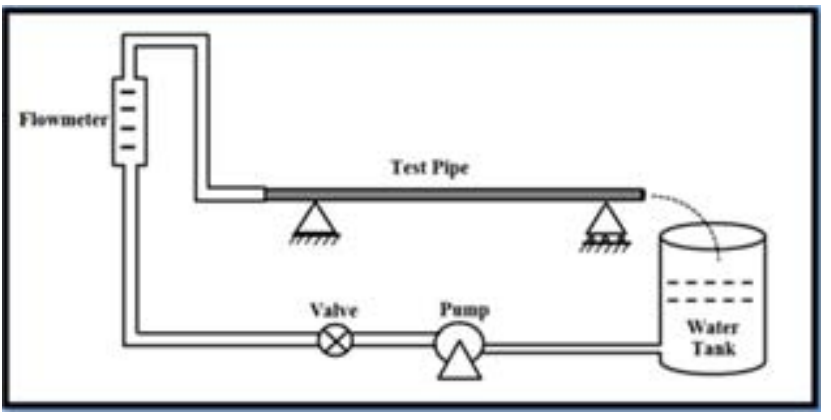

Figure 5: Schematic diagram of water circuit and the test model

\subsection{Instruments}

The block diagram of the various components of the electric vibration instrument are shown in Fig.(6).

The electrical vibration circuit can be divided into two main circuits; the first represents the "excitation side" which consists of: function generator, high voltage power amplifier and vibration exciter ( piezoelectric shaker). The second is the "response side" which includes: piezoelectric sensor and

\section{Volume 4 Issue 12, December 2015}




\section{International Journal of Science and Research (IJSR) \\ ISSN (Online): 2319-7064}

Index Copernicus Value (2013): 6.14 | Impact Factor (2014): 5.611

oscilloscope, as shown in Fig.(5-4) . A photograph of the electrical vibration instruments is shown in Fig. (5-6,7 , , , 9 and 10).

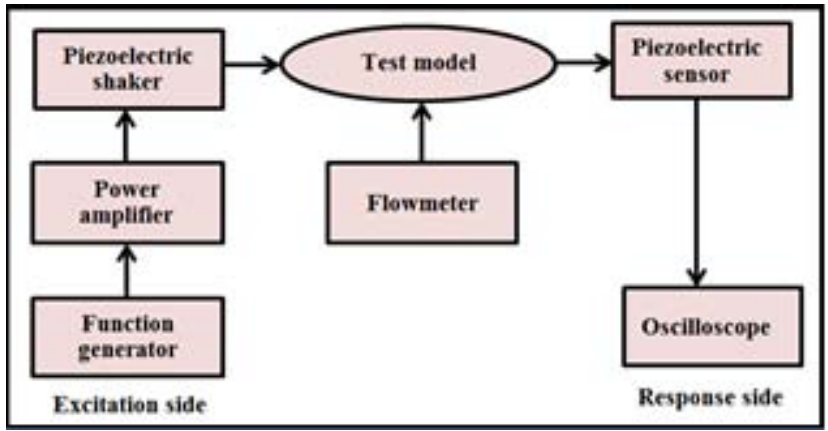

Figure 6: Block diagram of the measuring circuit

\subsubsection{High Voltage Amplifier of PZT (HVPZT).}

A power amplifier drives piezoelectric actuators through an applied voltage. The device used in the series of experiments featured in this work is a (Trek Model 2205) high voltage inverted operational amplifier. The device accepts an input signal and amplifies it up to \pm 500 Vpeak.It is stable to drive large capacitive loads, like piezoelectric actuators[9].

\subsubsection{Sensor and Shaker}

QUICKPACK MIDE QP20W double layer piezoelectric type is use as structural sensors transducers, actuator and shaker attaching them either directly to a data acquisition device. Piezoelectric shall be attached to the main structure by special piezoelectric adhesive. This type of piezoelectric can be used as sensor and actuator at same time[10]. Piezoelectric and adhesive are shown in appendix[Fig.(7)].

\subsubsection{Function Generator}

BK model 4075, a $25 \mathrm{MHz}$ arbitrary/Function generator, is a precision source of sine, triangle, square and pulse waveforms plus dc voltage. All can be externally modulated. Output can be continuous or can be triggered or gated by external signal or front panel switch. Amplitude of the waveforms is variable from $30 \mathrm{~V}$ down to $1.5 \mathrm{mV}$. DC reference of the waveform can be offset positively or negatively[11].

\subsubsection{Oscilloscope}

The digital oscilloscope $250 \mathrm{MHz}$ type GW-INSTEK GDS3000 is used with built-in FFT analyzer. This device is used to display the vibration waves and frequency results, which extract from the sensor, due to vibration of the structures.A $100 \mathrm{GSa} / \mathrm{s}$ ET sampling rate $(10 \mathrm{ps} \mathrm{pt}-\mathrm{pt}$ resolution) is provided to accurately reconstruct repetitive waveforms avoiding software interpolation distortion. Two high speed USB 2.0 Host ports located in both front panel and rear panel are used for easy access of stored data[11].

\subsection{Checking and Calibrations}

Prior to testing, the densities and modulus of elasticity of the test models were checked and the accuracy of the instruments was tested.

The various procedures for checking and calibration are as follow;

1. The modulus of elasticity for the test pipe models is checked by carrying out simple experiments. In these experiments the lowest two natural frequencies of the pipe models without fluid and under varies boundary conditions are measured. Then the modulus of elasticity is calculated from the following formula;

$$
E=m L^{4} \omega^{2} / I B \beta_{n}{ }^{2}
$$

Where;

$\beta_{1}=3.9267, \beta_{2}=7.0686$ are for fixed - simply pipes.

The span length of each model was $1 \mathrm{~m}$.

2. The densities of the model materials are checked by weighting a samples of length of $2 \mathrm{~cm}$ by using threedigit-electronic balance and applying the following formula :-

$$
\rho_{p}=\frac{4 m}{\pi\left(D_{o}^{2}-D_{i}^{2}\right) L}
$$

A comparison between the measured and tabulated values of the densities of the pipe models is given in Table (2). As it can be seen from this table, there are good agreements between the theoretical and experimental values of the density and modulus of elasticity for the all models

1) The accuracy of the flowmeter is tested in a calibration process .In this test the water is allowed to fill a reservoir of five liter capacity through the meter. The average time required for this process is recorded and the flow rate is calculated .The calculated flow rate is compared with the meter reading. The results gave good agreement.

2) The oscilloscope is calibrated by using the standard $1 \mathrm{kHz}$ square wave supplied with this instrument as a testing signal.

3) The accuracy of the function generator is checked by direct connecting its output to the oscilloscope input and comparing the labeled frequencies with the measured ones, the results showed a very good agreement

4) Finally for overall calibration, the electrical vibration system has been calibrated and tested by applying different values of excitation frequencies from the sine generator. Then the specified input values were compared with the output recorded electrical signal. High accuracy and identical results have been shown between these values.

\subsection{Checking and Calibrations}

In this test the two pipe models were employed .The three ends supports were arranged to fulfill the clamped-pinned, clamped-clamped and cantilever ends boundary conditions. For all models, the span length was $1 \mathrm{~m}$.

In measuring the natural frequencies, the test models were subjected to forced vibration under the action of the harmonic force generated by the piezoelectric shaker. The response of the pipe models was measured by the piezoelectric sensor and displayed via the oscilloscope.

In measuring the natural frequencies of any pipe models, the excitation frequency of the piezoelectric shaker is gradually increased from zero observing the response until a sharp amplitude (resonance) is reached.At this instant the

\section{Volume 4 Issue 12, December 2015}




\section{International Journal of Science and Research (IJSR) \\ ISSN (Online): 2319-7064 \\ Index Copernicus Value (2013): 6.14 | Impact Factor (2014): 5.611}

frequency is recorded as the first natural frequency .To measure the second natural frequency the piezoelectric shaker frequency is further increased until a second resonance is reached. The same procedures were repeated for the third natural frequency.

In case of cantilever pipes, the natural frequencies are complex as stated in the theoretical. The real parts denote the natural frequencies which can be measured, whereas the imaginary parts represent the attenuation in the natural frequencies due to the effect of the fluid damping, only[12]. However, in practice several types of damping take place like structural, coulomb and hysteresis damping which contribute with the fluid damping leading to a large error. For this reason only the real natural frequencies were considered in measuring the natural frequencies for cantilever pipes.

\section{Results and Discussions}

\subsection{Natural Frequency and Mode Shape}

The measured natural frequencies for the lowest three modes of the test model (PVC pipe) are presented in Table (3) .The model was tested under clamped-pinned, clamped-clamped and cantilever boundary conditions. The water flow rate was fixed at $40 \mathrm{~L} / \mathrm{min}$.For comparison purpose the corresponding theoretical and values of the natural frequencies, and the associated errors are given in the following tables . It shows good agreement between these results.

Table (3) indicate to errors between the theoretical and the experimental values of the natural frequencies. This can be attributed to the following:-

1)It is impossible to provide perfect boundary conditions in practice.

2)Many sources of errors such as instruments loading, reading,..etc.

3) Hose connection at the pipe inlet adds additional stiffness to the pipe models.

4)For more accurate measuring of the natural frequencies, the plot of the frequency response must be used; however such a test requires complicated measuring instruments.

Table 3: Experimental and theoretical natural frequencies of

\begin{tabular}{|c|c|c|c|c|c|c|}
\hline \multirow{3}{*}{$\begin{array}{l}\text { Boundary } \\
\text { conditions }\end{array}$} & \multirow{3}{*}{$\begin{array}{l}\text { Mode } \\
\text { No. }\end{array}$} & $\frac{\mathrm{e}\left(u_{0}=0.70\right.}{\text { Natur }}$ & $\begin{array}{l}\text { Natural frequency }(\mathrm{Hz}) \\
\end{array}$ & $\frac{.6336}{18)}$ & \multicolumn{2}{|c|}{ \%Error } \\
\hline & & \multirow{2}{*}{ Experimental } & \multicolumn{2}{|c|}{ Theoretical } & \multirow{2}{*}{ Analytical } & \multirow{2}{*}{ ANSYS } \\
\hline & & & Analytical & ANSYS & & \\
\hline \multirow{3}{*}{$\begin{array}{l}\text { Clamped } \\
\text { pinned }\end{array}$} & $\overline{11}$ & 13.4 & 13.7 & 14 & 2.23 & -4.47 \\
\hline & 2 & 41.6 & 44.74 & 46.04 & -7.54 & -10.6 \\
\hline & 3 & 87.4 & 93.28 & 96.6 & -6.72 & -10.5 \\
\hline \multirow{3}{*}{$\begin{array}{l}\text { Clamped- } \\
\text { clamped }\end{array}$} & 1 & 18.7 & 19.74 & 20.23 & 6.07 & 8.18 \\
\hline & 2 & 52.6 & 54.91 & 57.08 & -4.39 & -8.517 \\
\hline & 3 & 103.4 & 107.8 & 113.8 & -4.25 & -10.05 \\
\hline \multirow{3}{*}{ Cantilever } & 1 & 3.75 & $3.9+1.6989 \mathrm{i}$ & 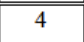 & -4 & "-6.66 \\
\hline & 2 & 21 & $21.9+1.6956 \mathrm{i}$ & 22.43 & -4.28 & -6.8 \\
\hline & 3 & 55.9 & $58.4+1.6862 \mathrm{i}$ & 61.4 & -4.472 & -9.83 \\
\hline
\end{tabular}

Fig. (8,9 and 10) shows the mode shapes of a cantilever, clamped-pinned and clamped- clamped pipe respectively.
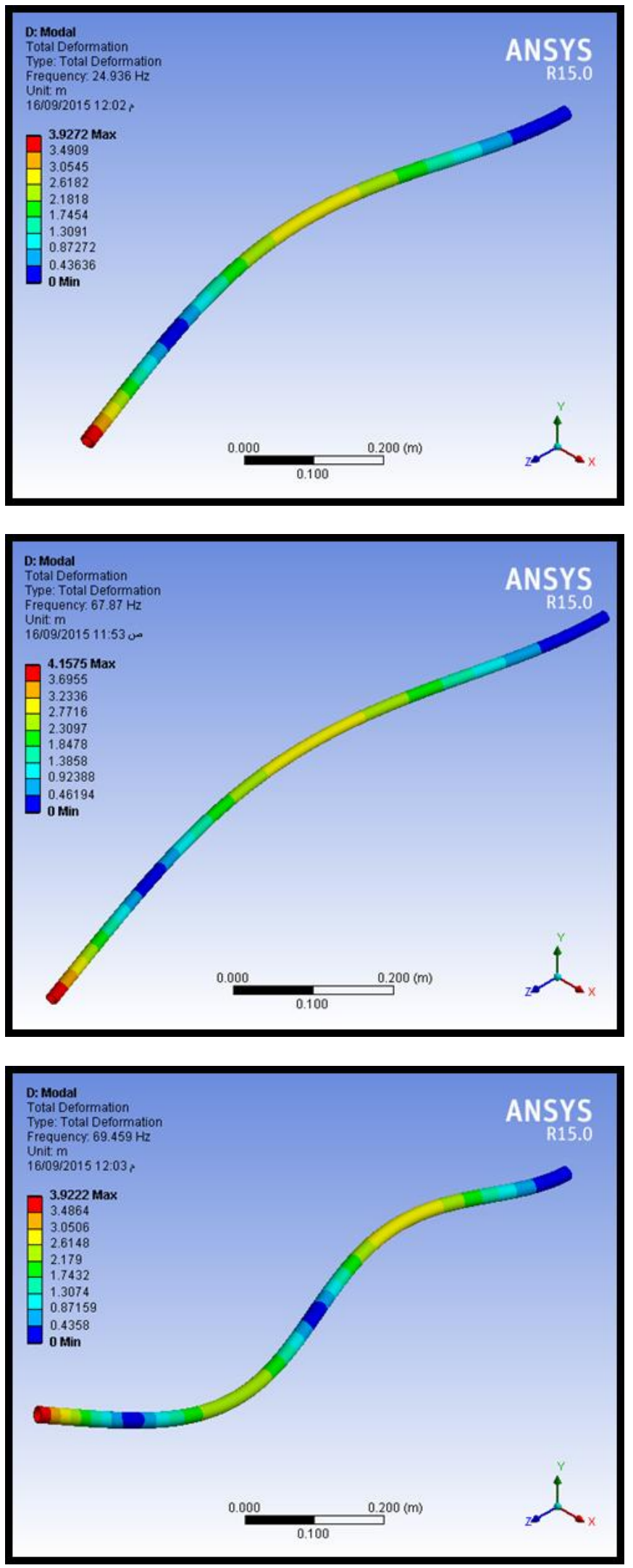

Figure 8: Mode shapes of a cantilever pipe conveying fluid 
International Journal of Science and Research (IJSR)

ISSN (Online): 2319-7064

Index Copernicus Value (2013): 6.14 $\mid$ Impact Factor (2014): 5.611
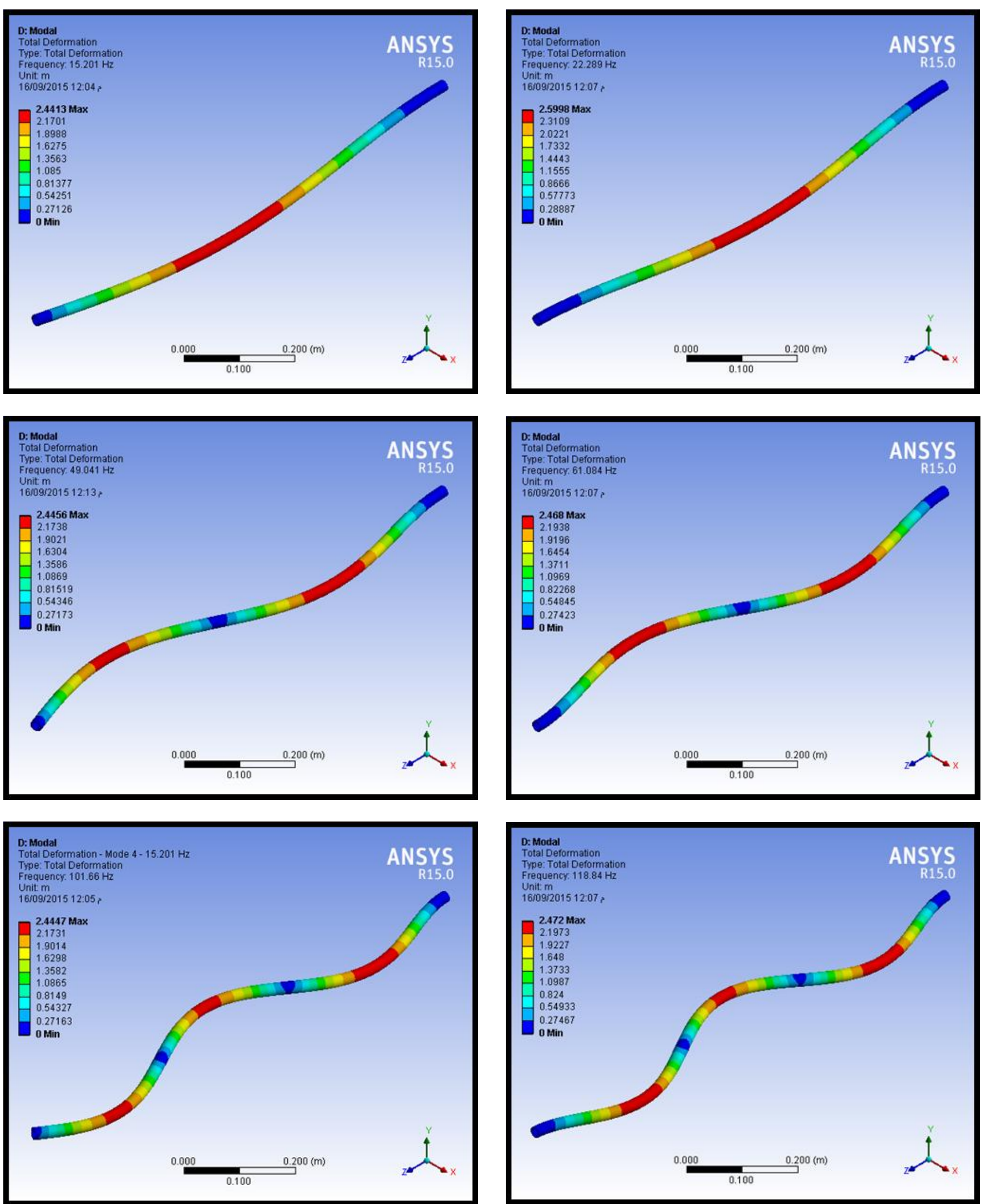

Figure 9: Mode shapes of a c-p pipe conveying fluid

Figure 10: Mode shapes of a c-c pipe conveying fluid

\subsection{Stress distribution due to Flowing Fluid}

The pressure distributions in a pipe conveying fluid (water) are shown in Figs. (11,12 and 13). The sample of calculations was made on aluminum pipe model at different boundary conditions. The fluid is assumed water entered a pipe with a flow rate $40 \mathrm{~L} / \mathrm{min}$. The fluid forces and solid displacements,

Volume 4 Issue 12, December 2015 


\section{International Journal of Science and Research (IJSR) \\ ISSN (Online): 2319-7064 \\ Index Copernicus Value (2013): 6.14 | Impact Factor (2014): 5.611}

velocities was transferred across the fluid-solid interface to produce stresses distributed along the pipe geometry. Fig. (14) shows the total deformation, Von Mises stress, and Von Mises total strain due to flowing fluid (water) for clampedpinned boundary conditions .

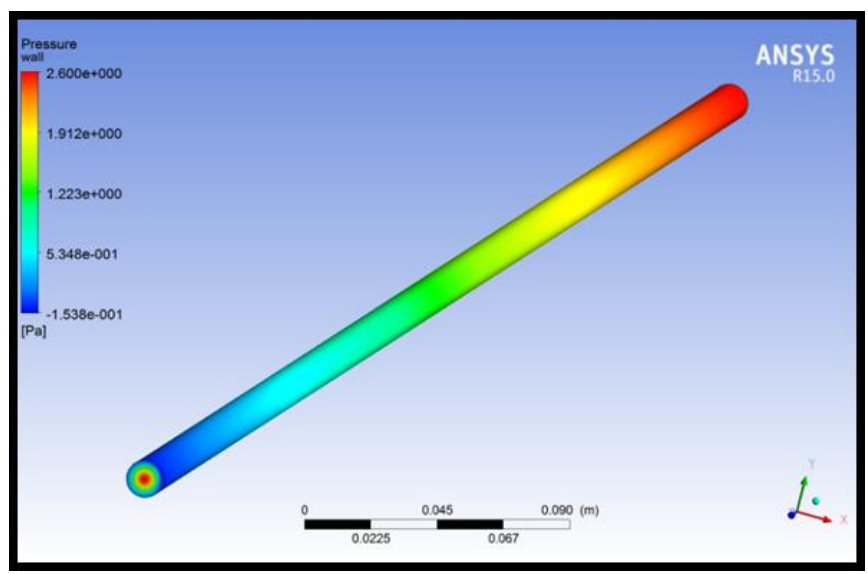

Figure 11: Pressure distribution along a wall pipe

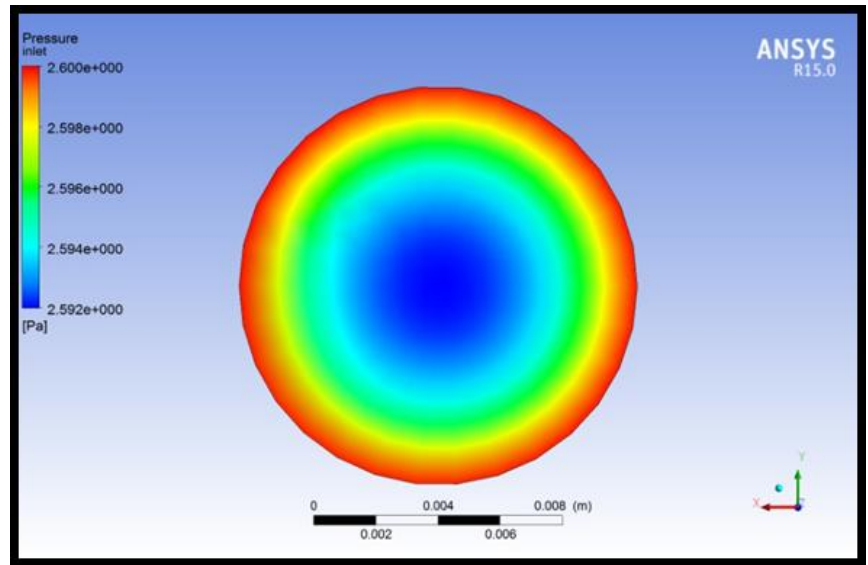

Figure 12: Pressure distribution at inlet of the pipe sections

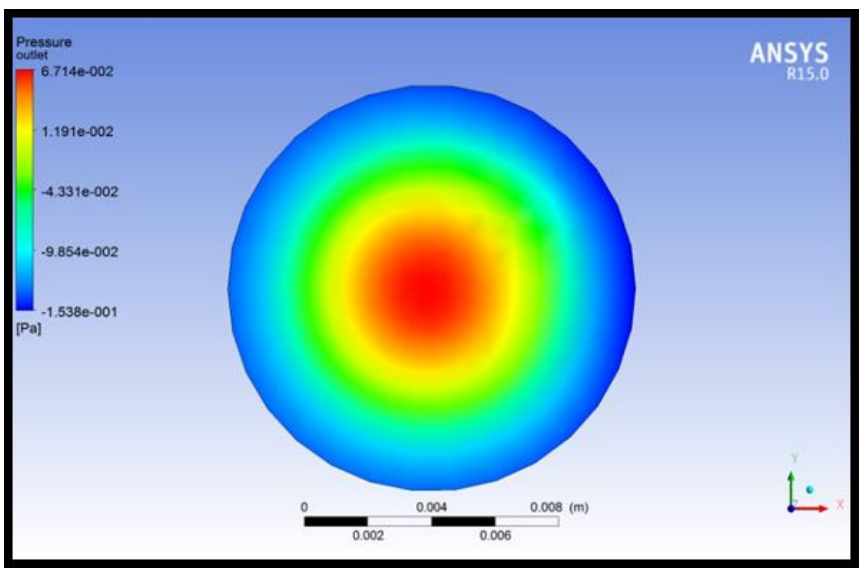

Figure 13: Pressure distribution at outlet of the pipe sections

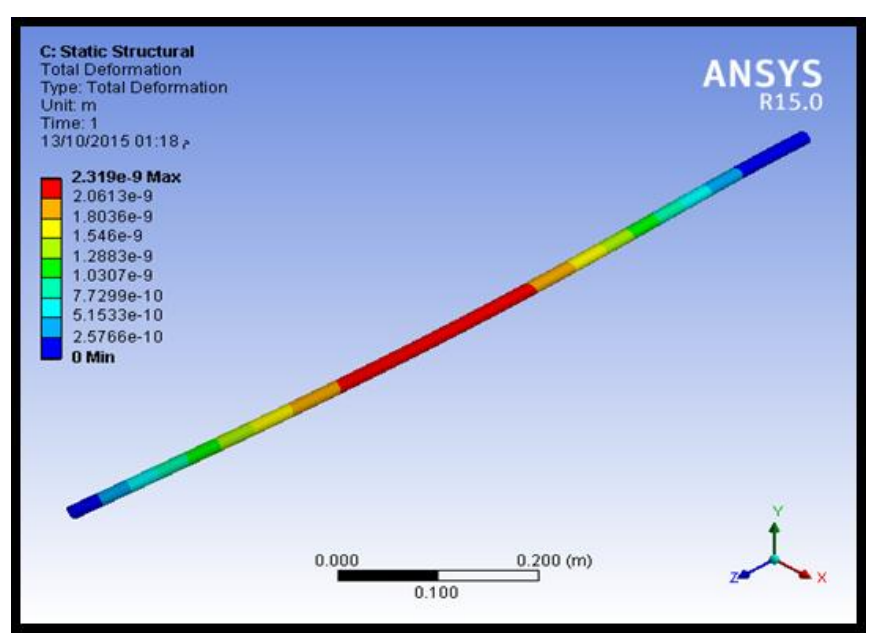

(a)

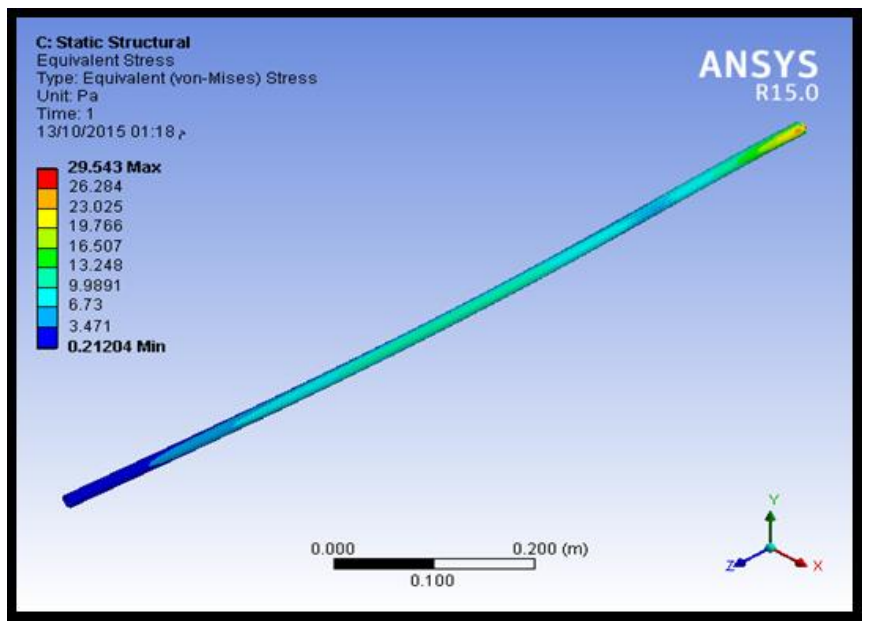

(b)

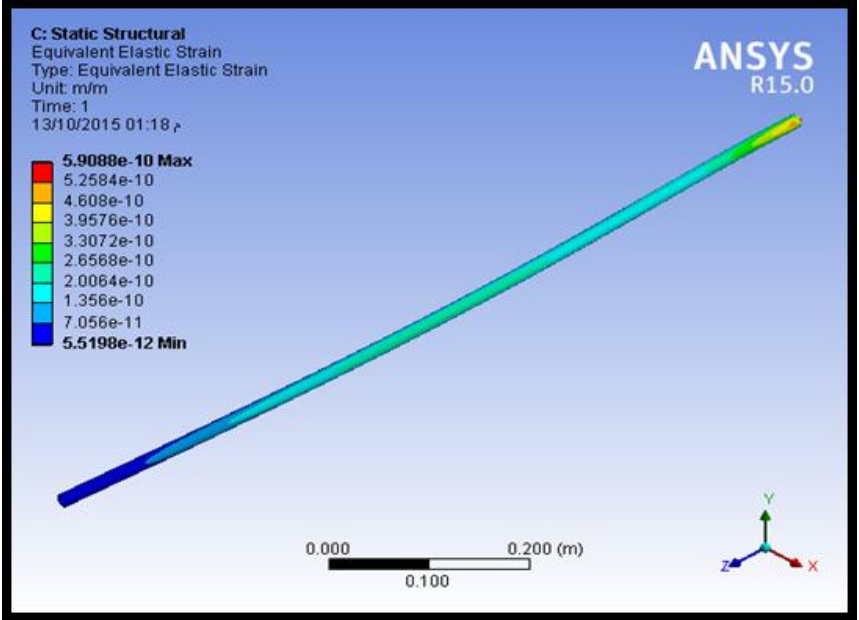

(c)

Figure 14: Clamped-pinned boundary conditions (a): Total deformation (b): Von Mises stress (c): Von Mises total strain

\subsection{Effect of Fluid Velocities on the Natural Frequencies}

In Figs.(15 to 17), the theoretical and experimental natural frequencies of the model are presented .The lowest three natural frequencies in $\mathrm{Hz}$ were measured at water flow rate of $10,20,30,40,50,60$ and $70 \mathrm{~L} / \mathrm{min}$ for clamped-pinned, clamped-clamped and cantilever boundary conditions. In general, these figures show that the measured natural

Volume 4 Issue 12, December 2015 


\section{International Journal of Science and Research (IJSR) \\ ISSN (Online): 2319-7064 \\ Index Copernicus Value (2013): 6.14 $\mid$ Impact Factor (2014): 5.611}

frequencies decrease with the increasing of the fluid flow rate and hence the fluid velocity. This is the case for any mode and boundary conditions. The drift between the measured and the theoretical values is due to the experimental errors stated previously.
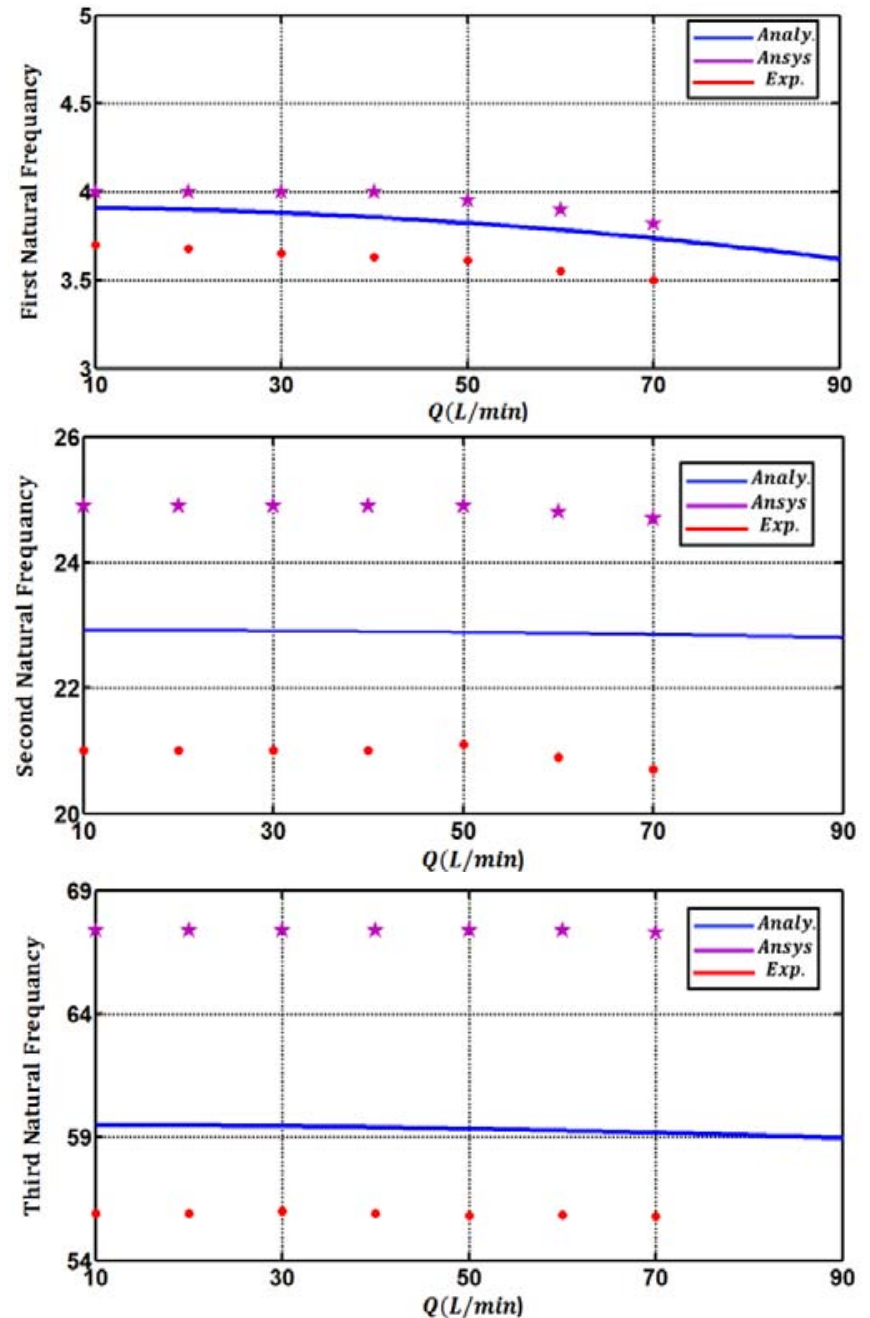

Figure 15: Effect of flow rate on the lowest three natural frequencies of cantilever pipe

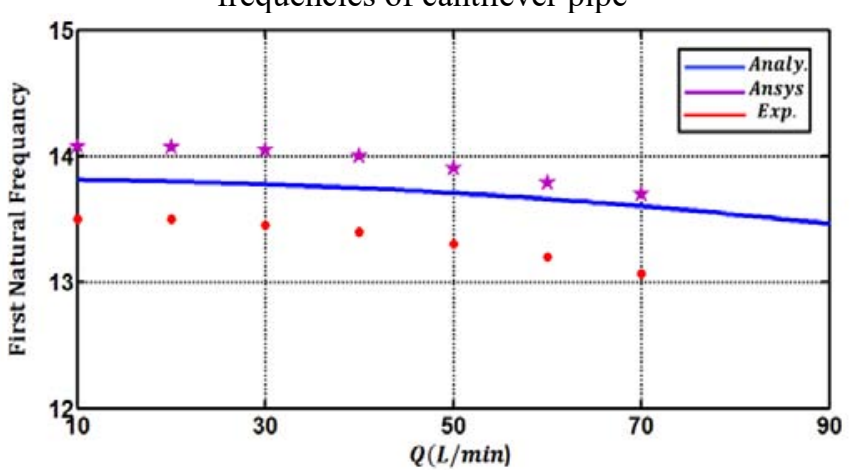

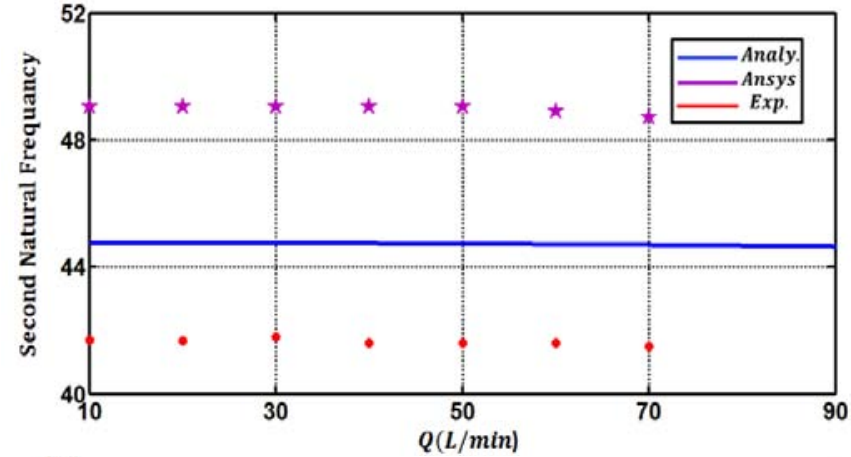

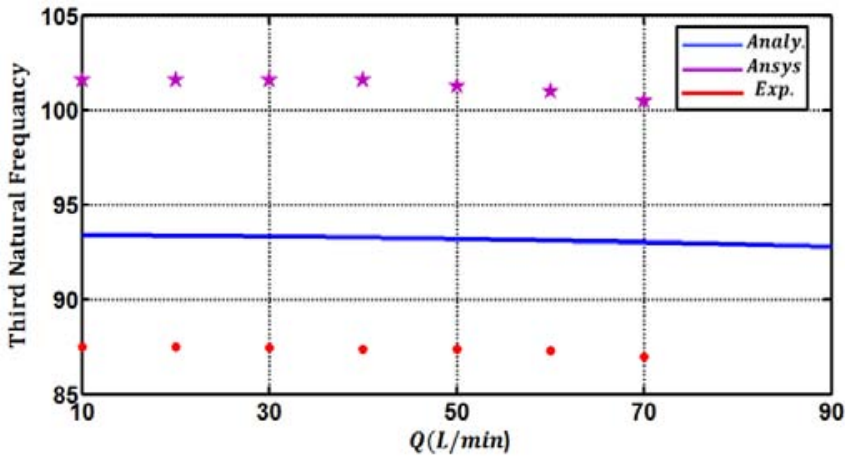

Figure 16: Effect of flow rate on the lowest three natural frequencies of c-p pipe.
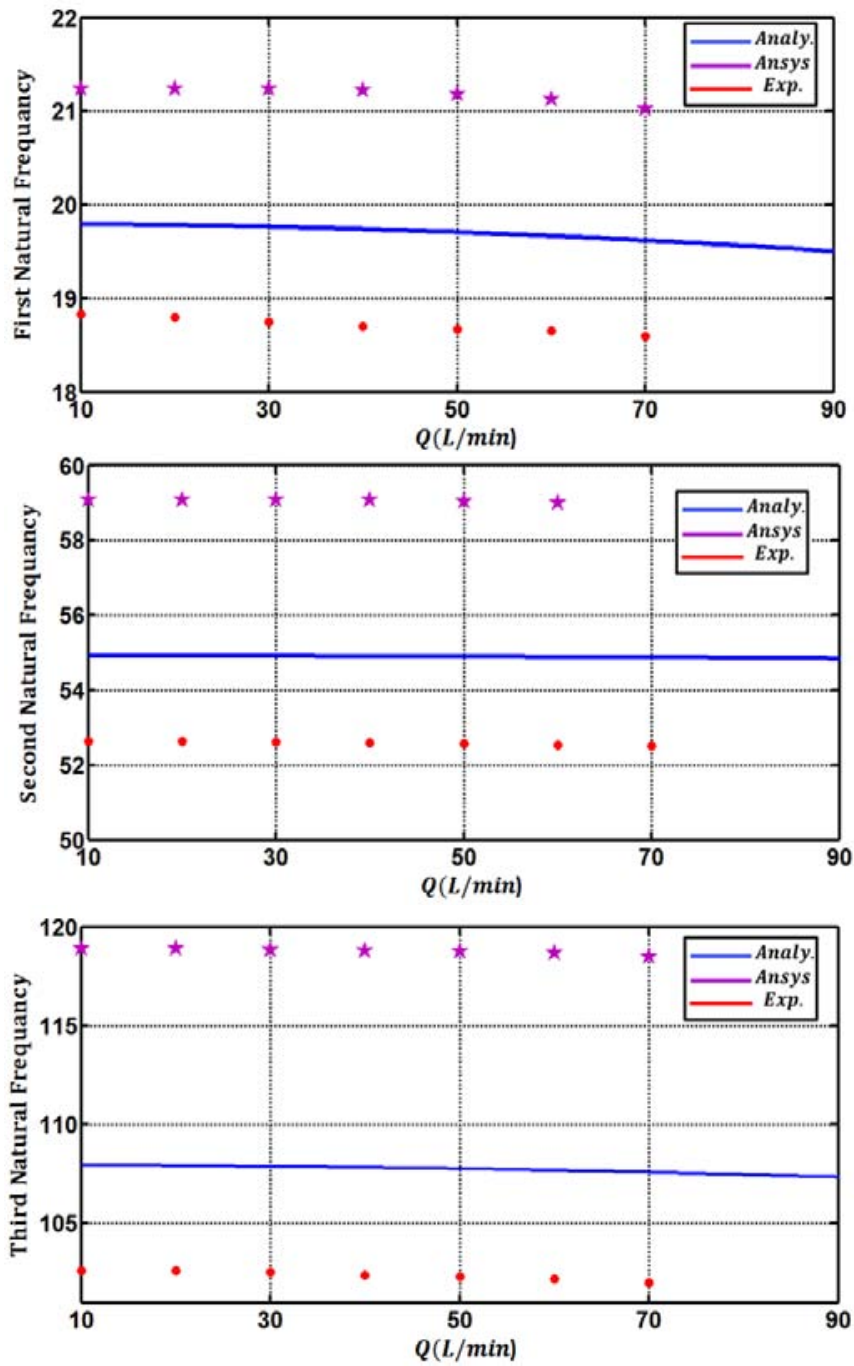

Figure 17: Effect of flow rate on the lowest three natural frequencies of c-c pipe

Volume 4 Issue 12, December 2015 


\section{International Journal of Science and Research (IJSR) \\ ISSN (Online): 2319-7064}

Index Copernicus Value (2013): 6.14 | Impact Factor (2014): 5.611

\section{Conclusions}

1)The general solution for the vibration equation of conservative pipes conveying fluid is derived in this article. From this solution the frequency equations for cantilever, clamped-pinned and clamped-clamped pipes conveying fluid are obtained analytically in terms of the pipe parameters.

2) The fluid flow velocity generally, reduces the natural frequencies of the pipe conveying fluid. Very little effect was observed for the velocity ranges used.

3) The experimental results show satisfactory agreement with the theory many aspects of the dynamical behavior of pipe conveying fluid were observed experimentally such as: the decrease in natural frequencies with increasing of the fluid velocity.

\section{References}

[1] Paidousiss M.P." The Canonical Problem of the FluidConveying Pipe and Radiation of the Knowledge Gained to other Dynamics Problems Across Applied Mechanics." J. Sound Vib. Vol.310, 462-492, 2008.R. Caves, Multinational Enterprise and Economic Analysis, Cambridge University Press, Cambridge, 1982. (book style)

[2] Paidousiss, M.P. "Dynamics of flexible slender cylinders in axial flow. Part 1theory. "Journal of Fluid Mechanics, Vol.26, 717-736.1966H.H. Crokell, "Specialization and International Competitiveness," in Managing the Multinational Subsidiary, H. Etemad and L. S, Sulude (eds.), Croom-Helm, London, 1986. (book chapter style)
[3] Paidoussis M. P. ," Fluid-Structure Interactions: Slender Structures and Axial Flow", 1. New York: Academic Press; 1998.

[4] Al-Rajihy A.A, "Out-of-plane vibration of an intermediately supported curved tube conveying fluid",M.Sc Thesis, University of Baghdad,1990.

[5] M.P.Paidoussis and N.T.Issid "Dynamic stability of pipes conveying fluid",Journal of Sound and Vibration Vol.33,No.3,page 267-817,1974.

[6] S.R.Chary,C.K.Rao and R.N.Iyengar "Vibration of fluid conveying pipe on Winkler foundation", proceeding of the 8th national convention of Aerospace enginners on Aeroelastically,IIT Kharagpur, India, 1993.

[7] T. P. Shurtz, "Analysis of Induced Vibrations in FullyDeveloped Turbulent Pipe Flow Using a Coupled LES and FEA Approach," MSc Thesis, Provo, Utah: Brigham Young University, 2009.

[8] Ansys CFX V 12.0 Users Manual.

[9] Trek Model 2205 Piezo Driver/Power Amplifier.

[10] PACKAGED PIEZOELECTRIC ACTUATORS AND SENSORS (Mide QuickPack product)

[11] Z. Shi, G. Ma, and Q. Hu, "A hybrid control scheme of vibration reduction of flexible spacecraft during attitude maneuver" 1st International Symposium on Systems and Control in Aerospace and Astronautics, pp. 169174, Jan. 2006.

[12] Sundraraian C., "On the Stability of Divergence-Type Elastic Systems", Devel. Theoret. Appl. Mech. Washington. D.C.,475-481,1974.

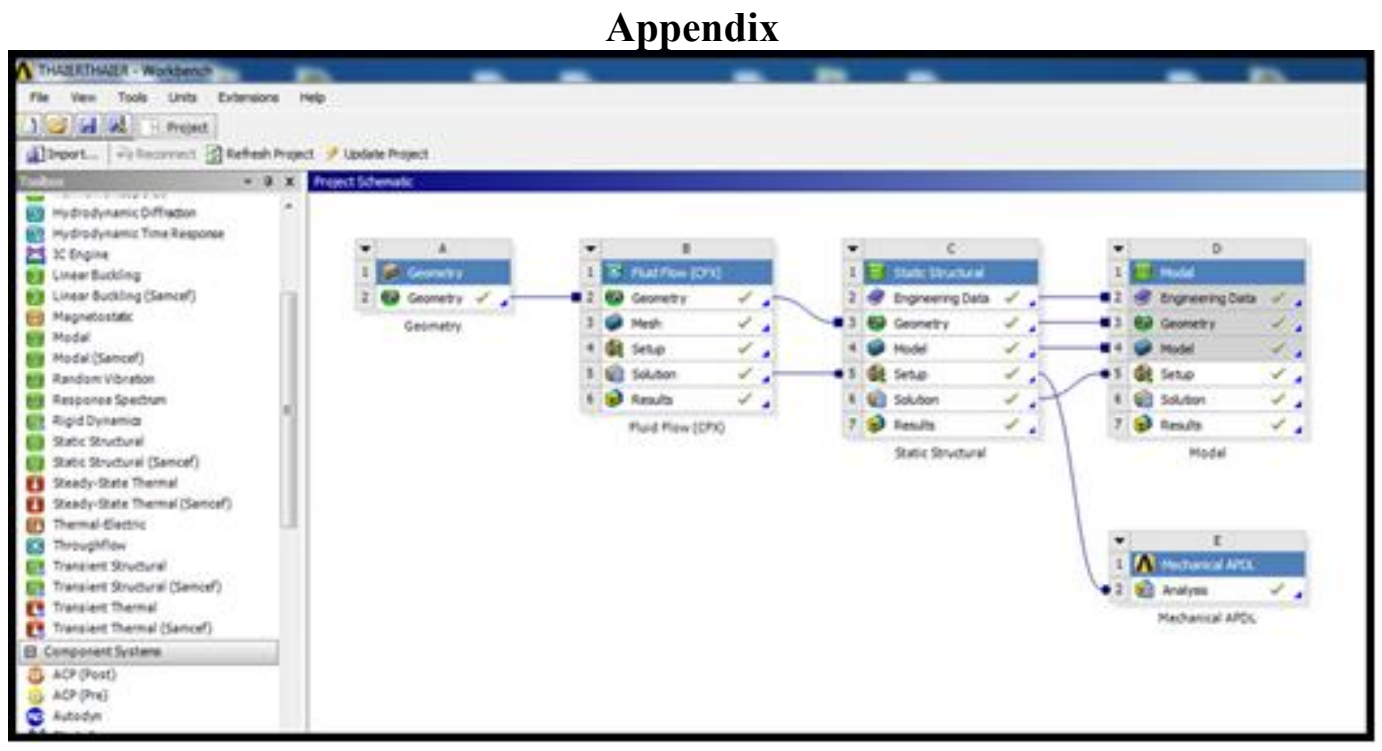

Figure 1: ANSYS workbench (multi-stage work).

Table 2: Measured and tabulated properties of the tested model

\begin{tabular}{|c|c|c|c|c|c|c|}
\hline \multirow{3}{*}{ Material } & \multicolumn{3}{|c|}{$\mathbf{\rho}$} & \multicolumn{3}{c|}{$\mathbf{E}$} \\
& $\mathbf{k g} / \mathbf{m} 3$ & \multicolumn{3}{c|}{$\mathbf{m}^{\mathbf{2}}$} \\
\cline { 2 - 7 } & Tabulated & Measured & \%Err. & Tabulated & Measured & $\%$ Err. \\
\hline PVC & 1000 & 975 & -2.5 & 7.12 & 6.83 & -4.24 \\
\hline
\end{tabular}


International Journal of Science and Research (IJSR)

ISSN (Online): 2319-7064

Index Copernicus Value (2013): 6.14 | Impact Factor (2014): 5.611

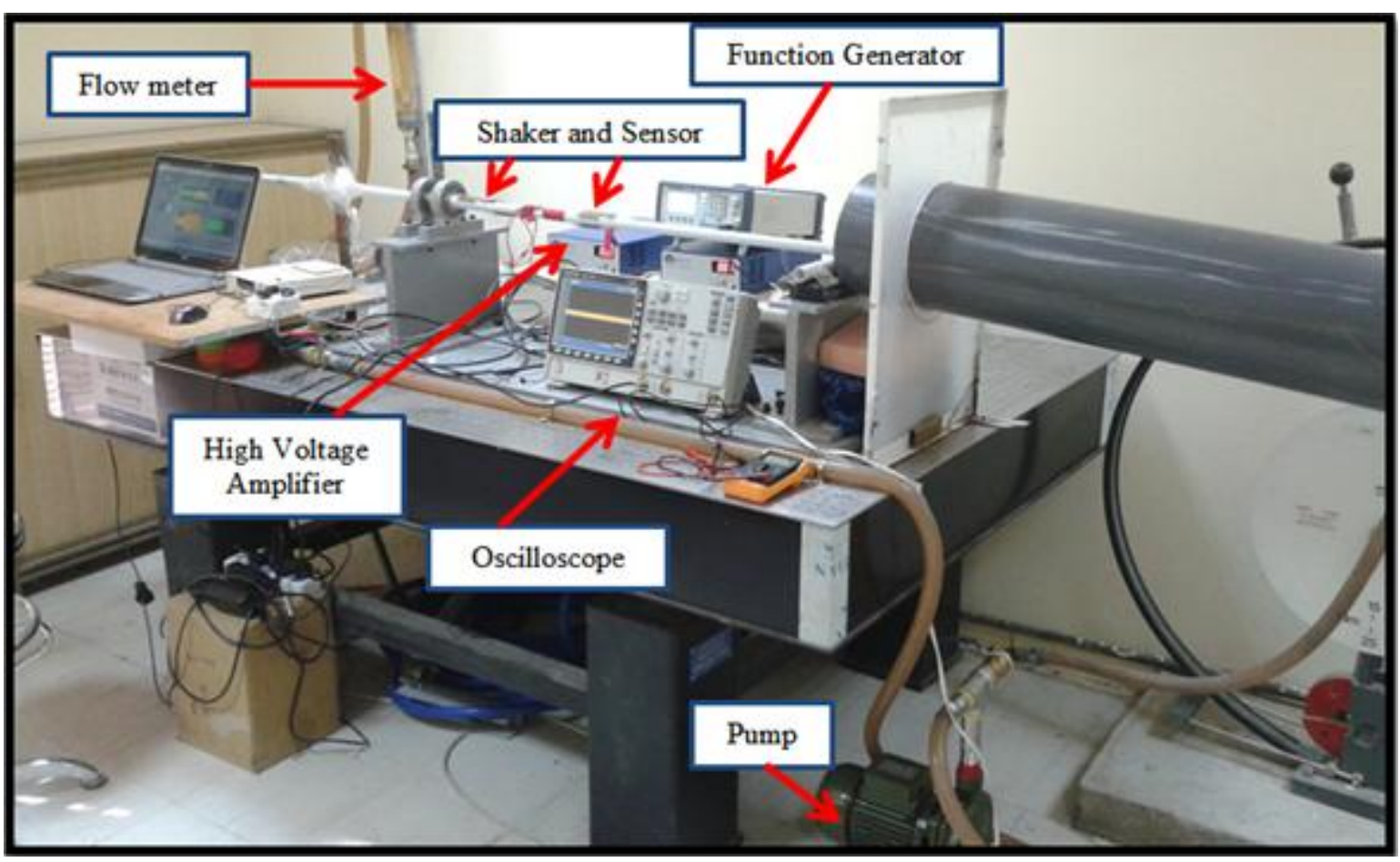

Figure 2: Modal structure of pipe conveying fluid

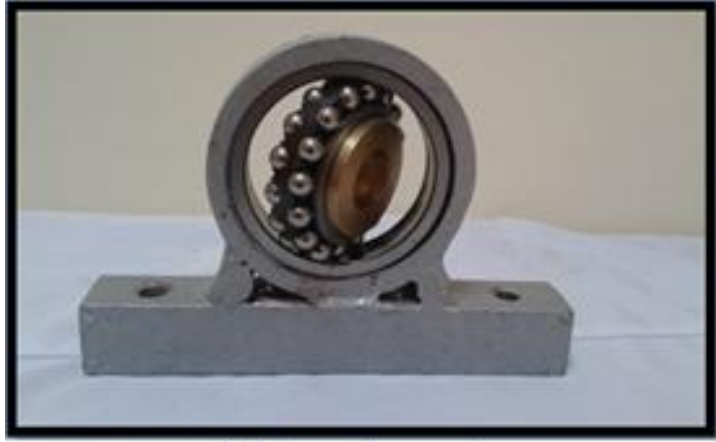

(a): Pinned support

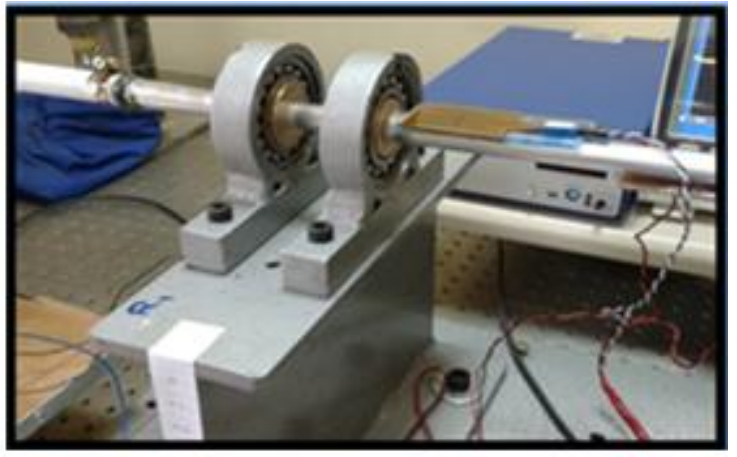

(b): Clamped Support

Figure 4: A photograph of the supports.
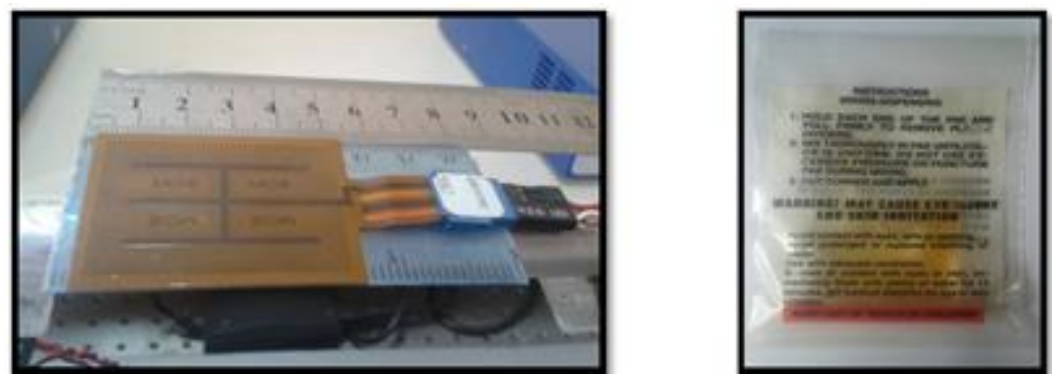

Figure 7: A photograph of the piezoelectric and structural epoxy resin.

Volume 4 Issue 12, December 2015

www.ijsr.net 
International Journal of Science and Research (IJSR)

ISSN (Online): 2319-7064

Index Copernicus Value (2013): 6.14 $\mid$ Impact Factor (2014): 5.611

\begin{tabular}{|c|c|c|c|c|}
\hline & Pinned-Pinned & Clamped-Clamped & Clamped-Pinned & Cantilever \\
\hline$k_{5}$ & $\mathbf{0}$ & $\mathbf{0}$ & $\mathbf{0}$ & $+12 m r u_{o}$ \\
\hline$k_{4}$ & $\begin{array}{l}-138.175 H \\
+9546.1 \\
+120.608 r^{2} u_{n}^{2}\end{array}$ & $\begin{array}{l}157.258 \mathrm{H} \\
+18922 \\
+166.388 \mathrm{mr}^{2} u_{n}{ }^{2}\end{array}$ & $\begin{array}{l}148.447 H \\
+13601.8 \\
+142.275 m r^{2} u_{n}{ }^{2} \\
\end{array}$ & $\begin{array}{l}-58.3405 H \\
+4304.44 \\
+114.502 m r^{2} u_{n}{ }^{2}\end{array}$ \\
\hline$k_{3}$ & 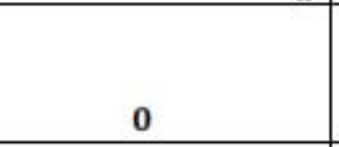 & 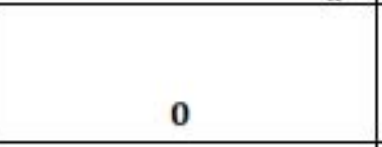 & $\begin{array}{l}+0.003 T m r u_{o} \\
-0.001 m r^{3} u_{o}{ }^{3}\end{array}$ & $\begin{array}{l}+374.357 T m r u_{o} \\
-432.196 m r^{3} u_{o}{ }^{3} \\
-34435.5 m r u_{o}\end{array}$ \\
\hline$k_{2}$ & $\begin{array}{l}+3436.55 m r^{2} u_{o}{ }^{2} H \\
-233439 m r^{2} u_{o}{ }^{2} \\
-4773.04 H^{2} \\
555683 H \\
-0.132176 * 10^{8}\end{array}$ & $\begin{array}{l}+4481.05 m r^{2} u_{o}{ }^{2} H \\
-714029 m r^{2} u_{o}{ }^{2} \\
-6243.22 H^{2} \\
0.134854 * 10^{7} H \\
-0.648214 * 10^{8}\end{array}$ & $\begin{array}{l}+4030.57 m r^{2} u_{o}{ }^{2} H \\
-416514 m r^{2} u_{o}{ }^{2} \\
-5516.43 H^{2} \\
887358 H \\
-0.303083 * 10^{8}\end{array}$ & $\begin{array}{l}+565.864 m r^{2} u_{o}{ }^{2} H \\
-123009 m r^{2} u_{o}{ }^{2} \\
-567.72 H^{2} \\
69941.7 H \\
-0.190122 * 10^{7}\end{array}$ \\
\hline$k_{1}$ & $\mathbf{0}$ & $\mathbf{0}$ & $\begin{array}{c}-0.0613238 T m r u_{o} \\
\quad+0.005 T^{2} m r u_{n}\end{array}$ & $\begin{array}{c}-154473 T m r u_{o} \\
+1835.27 T^{2} m r u_{o} \\
+\left(7604890 * 10^{7} m r u_{o}\right)\end{array}$ \\
\hline$k_{0}$ & $\begin{array}{l}-34609.9 H^{3} \\
+0.478222 * 10^{7} H \\
-0.165195 * 10^{9} \mathrm{H} \\
+0.119786 * 10^{10}\end{array}$ & $\begin{array}{l}-51673 H^{3} \\
+0.148296 * 10^{8} H^{\prime} \\
-0.120933 * 10^{10} \\
+0.278330 * 10^{11} \\
\end{array}$ & $\begin{array}{l}-43139.2 H^{3} \\
+0.877896 * 10^{7} H^{2} \\
-0.478995 * 10^{9} H \\
+0.645029 * 10^{10} \\
\end{array}$ & $\begin{array}{l}+441.872 H^{3} \\
+8265.4 H^{2} \\
+684784 H \\
+0.228488 * 10^{8} \\
\end{array}$ \\
\hline
\end{tabular}

Volume 4 Issue 12, December 2015

www.ijsr.net 